\title{
SOBRE LA LÓGICA DE LAS NORMAS
}

\author{
Enzo Solari Alliende \\ Profesor de Filosofía del Derecho en la \\ Universidad Católica del Norte
}

A partir de los años 50 de este siglo se ha producido un desarrollo vertiginoso de las investigaciones concernientes a la lógica jurídica $y$, en general, a la lógica normativa. Tales investigaciones no son ajenas al análisis de los actos de habla que ha venido realizando la filosofía del lenguaje, utilizan, además, tanto los instrumentos de la lógica formal contemporánea cuanto los de las "lógicas razonables" (entiéndase tópica, retórica, hermenéutica, etc.) y, támbién, dicen relación con las normas y, a la vez, con los enunciados o razonamientos que recaen sobre ellas ${ }^{153}$. Ahora bien: el estado de la cuestión en estas materias -sobretodo por lo que toca a los intentos de constituir un sistema deductivo, axiomatizado y formalizado de lógica normativa o deóntica- es particularmente polémico y carente de zonas pacíficas. En lo que sigue, no haré más que mostrar a título ejemplar algunos desarrollos contemporáneos de la lógica normativa, sobretodo en su vertiente formal.

\section{La vía de la lógica estricta}

Es un hecho inconcuso que se ha intentado desde muy antiguo una lógica práctica o directiva, aunque sea mediante puros atisbos. Aristóteles, Leibniz y Husserl, entre varios otros, dan cuenta de ello. Mas, los primeros esfuerzos contemporáneos de elaboración de una lógica deóntica, en la línea de la lógica axiomática y formal abierta por Morgan, Boole, Schröder, Peano y Frege, son, según muchos, los de von Wright, Becker, Sesmat y Blanché, García Maynez, Klug, Kalinowski y Castañeda, luego de los

\footnotetext{
${ }^{153}$ Para reafirmar lo dicho, cito un par de opiniones en el mismo sentido. Bobbio señala que en la lógica jurídica contemporánea se han constituido dos ramas bien distintas: una, la lógica de los juristas, ocupada con los razonamientos propiamente jurídicos, y otra, la lógica del derecho o deóntica, cuyo objeto es la estructura de las proposiciones normativas (dentro de los cuales Bobbio incluye, recién en la década de los 60, a Hofstadter, Jörgensen, Mckinsey, Menger, Ross, García Maynez, von Wright, Becker, Hare, Hall, Kalinowski, Weinberger, Anderson, Prior, Rescher, Dawson, Allen, Castañeda, Bohnert, Visalberghi, Hintikka, Apostel). Respecto de la primera, Bobbio reconoce que el discurso jurídico ha sufrido la aplicación de la moderna lógica simbólica, tal como se aprecia en Klug, Garcia Maynez, Magni, Tammelo y Paradies. Por otra parte, añade Bobbio, dicha lógica de los juristas conoce diversas versiones: una, la de los que piensan que ha de haber lógica, pero con un papel limitado (así, Loevinger, Klug, Magni, Guest); otra, la de los que, dando por equivalentes razonamiento lógico y razonamiento deductivo, dicen que hay que precisar cuál es el lugar del razonamiento deductivo en la ciencia jurídica (así, Miró Quesada, Kalinowski); y otra más, la de los que postulan que no hay una lógica de los juristas, si por lógica ha de entenderse un razonamiento demostrativo y matemático, sino más bien argumentación, retórica (así, Perelman).

Hernández Gil, por dar otro ejemplo, dice que en la lógica juridica pueden distinguirse dos grandes posturas. "De un lado queda aquel sector del pensamiento que confiesa... cómo en la esfera de lo jurídico sólo es posible un tipo de argumentación que, al dar entrada a lo intuitivo y a lo emocional, no es susceptible de la rigurosa esquematización lógica. De otro lado queda un importante sector... que considera aplicable al razonamiento juridico la lógica formal y simbólica, ya de manera plena e indiferenciada, ya con algunas variantes o modalidades, con lo que surge la categoría de la lógica deóntica".
} 
cuales las investigaciones en esta materia han experimentado una notable multiplicación ${ }^{154}$.

Los cultores de la lógica de las normas se hallan con diversos problemas. En primer término, la cuestión del ser de las normas: ¿qué son las normas? En este sentido, ha de esclarecerse qué tipo de fenómeno lingüístico -o expresión- es la norma, fijando la atención en las proposiciones propiamente normativas y haciendo una comparación entre éstas y las demás proposiciones, especialmente con proposiciones como son las imperativas, a veces consideradas idénticas a las normativas, y otras, sólo semejantes. En estas tareas, por cierto, suelen utilizarse herramientas sintácticas, semánticas (así, se pretende aislar la estructura semántica de la norma) y pragmáticas.

En segundo término, surge la cuestión de la distinción o indistinción de normas y enunciados acerca de normas. Cuestión que origina asertos tales como que los enunciados normativos -que no las normas- pueden ser verdaderos o falsos, o que las normas mismas -independientemente de los enunciados respecto de ellas- son verdaderas o falsas o, también, que las normas poseen valores análogos a los de verdad y falsedad (como, por ejemplo, los de validez e invalidez).

En tercer lugar, habida cuenta de todos estos problemas, emergen varias y fundamentales inquietudes. ¿Cuáles son las tareas y fronteras que definen a la lógica? ¿Es posible una estricta lógica de las normas y razonamientos normativos, una lógica deóntica? Ésta es la pregunta involucrada en el dilema de Jörgensen, a la cual este autor, en la segunda mitad de los años 30, respondió negativamente. Dicho dilema podría plantearse en los siguientes términos: si sólo los enunciados teóricos tienen valor lógico, ya que sólo ellos pueden ser verdaderos o falsos, entonces los razonamientos en los que se ligan proposiciones normativas no serían susceptibles de tratamiento lógico, por lo cual la concepción tradicional de la lógica no experimentaría modificaciones; pero si los raciocinios en los que se enlazan enunciados normativos también pueden ser tratados lógicamente, entonces habría que modificar la concepción tradicional de la lógica. Pero hay más cuestiones. En caso de ser posible, ¿cómo podría construirse una lógica axiomatizada y formalizada, no ya de enunciados, sino de normas? ¿Qué decir de la idea de Kelsen: no hay lógica de las normas, sólo hay lógica de las proposiciones normativas?

Para ilustrar el convulsionado panorama que ofrece la lógica deóntica, haré una reseña -breve e incompleta- de dos de los sistemas más importantes que se han construido a este respecto, los de von Wright y Kalinowski.

a) Primero, expongo algunas líneas básicas del pensamiento de Georg Henrik von Wright, tal como aparece en Norma y acción. Pero antes, conviene señalar, como lo recuerda Ballester, que este autor, con antelación y también con posterioridad a la obra citada, desarrolló la analogía entre la lógica modal y la lógica deóntica, rasgo al parecer característico de la mayoría de los fundadores de la lógica normativa. Von Wright, en este sentido, dividió los conceptos modales en conceptos aléticos o de

\footnotetext{
${ }^{154}$ Para formarse una opinión aproximada del volumen que ha ido alcanzando la investigación en lógica estrictamente deóntica, pueden consultarse las bibliografias que aparecen en Derecho y lógica, de Bobbio y Conte, Lógica del discurso normativo, de Kalinowski, Kelsen y la lógica jurídica formal, de Manson, y Análisis lógico y derecho, de Alchourrón y Bulygin, los tres primeros escritos respectivamente a inicios de los años 60,70 y 80 , mientras que el último, publicado a inicios de los 90 , recoge artículos escritos entre los años 60 y 90 .
} 
verdad (que son los de necesario, posible y contingente), conceptos epistémicos o de conocimiento (verificado, no decidido y falsado), conceptos deónticos o de obligación (obligatorio, permitido y prohibido) y conceptos existenciales (universalidad, existencia y vaciedad). Esta lógica modal, por ello, había de desdoblarse en cuatro ramas: lógica alética, lógica epistémica, lógica existencial y lógica deóntica.

En Norma y acción, von Wright distingue tres grandes tipos de normas:

- las reglas: son una peculiar clase de normas, pues no son prescriptivas ni descriptivas (y es el caso de las reglas del juego, de la gramática, de la lógica y de las matemáticas).

- las prescripciones: son las normas que consisten en mandatos, permisos y prohibiciones dados por una autoridad a algunos sujetos, debidamente promulgados y acompañados de una sanción (como, por ejemplo, las leyes estatales).

- las directrices o normas técnicas: son aquellas normas que, distintas de las normas hipotéticas, conciernen a los medios para alcanzar fines humanos. de normas:

Pero, además, dice von Wright que hay otros tantos tipos, menos importantes,

- las costumbres,

- los principios morales, y

- las reglas ideales (de ser, no de hacer).

Luego, von Wright construye una lógica del cambio. Siendo ' $p$ ' y ' $q$ ' variables que indican estados de cosas (como 'ventana abierta' y 'cigarrillo encendido'), '- $p$ ' y 'q' variables que indican los estados de cosas opuestos ('ventana cerrada' y 'cigarrillo apagado') y ' $T$ ' un símbolo que indica la sucesión temporal o paso de un estado de cosas, ubicado a su izquierda, a otro, colocado a su derecha, von Wright admite cuatro tipos de cambio o transformaciones de estado elementales, mutuamente excluyentes y conjuntamente exhaustivas:

$$
\begin{aligned}
& \mathrm{pT} p=\text { conservación (la ventana permanece abierta) } \\
& \mathrm{pT}-\mathrm{p}=\text { desaparición (la ventana se cierra) } \\
& -\mathrm{ptp}=\text { aparición (la ventana se abre) } \\
& -\mathrm{p} T-\mathrm{p}=\text { falta de aparición (la ventana permanece cerrada) }
\end{aligned}
$$

Enseguida, von Wright aborda los actos y las habilidades, para después elaborar una lógica de la acción (en la que, dados los límites de esta breve exposición, no se entrará). Siendo 'd' la acción positiva, ' $f$ ' la acción negativa u omisión, acto elemental aquella acción que tiene por resultado un cambio elemental y abstención elemental aquella acción que un agente, en determinada ocasión, de hecho no hace, si y sólo si podía hacerla (cuyo resultado, por lo tanto, es que ciertos cambios no tienen lugar), von Wright dice que hay cuatro actos elementales y cuatro abstenciones elementales, lo que da ocho tipos de acciones elementales:

$\mathrm{d}(-\mathrm{p} T \mathrm{p})=$ hacer $\mathrm{p}$ (abrir la ventana): la realización de este actorequiere dos condiciones. Una: el estado - $p$ debe darse en laprimera de las dos ocasiones sucesivas 
(porque sólo una ventana cerrada puede abrirse). Y la otra: el cambio -pTp debe ser resultado de acto de algún agente (el acto de abrir la ventana).

$d(p T-p)=$ destruir $p$ (cerrar la ventana): se requieren dos condiciones: el estado $p$ debe darse en la primera de las dos ocasiones sucesivas y no cambiar sino por el acto de un agente.

$d(p T p)=$ conservar $p($ la ventana permenece abierta): el estado $p$ se da inicialmente y cambiaría a su estado contradictorio si no fuera por el impedimento introducido por la acción de un agente.

$\mathrm{d}(-\mathrm{p} T-\mathrm{p})=$ supresión de $\mathrm{p}$ (la ventana permanece cerrada) : el estado $-\mathrm{p}$ se da inicialmente y se cambiaría a p si no fuera por el impedimento introducido por la acción de un agente.

$f(-p T p)=$ abstenerse de hacer $p$ : esta abstención, que conduce a - $p T-p$, sólo es posible si el estado - $p$ (ventana cerrada) no puede cambiar por sí solo al estado $p$ (ventana abierta).

$f(p T-p)=$ abstenerse de destruir p: esta abstención, que conduce a pTp, sólo es posible si el estado $\mathrm{p}$ no cambia por sí mismo a -p.

$\mathrm{f}(\mathrm{p} T \mathrm{p})=$ abstenerse de conservar $\mathrm{p}$ : esta abstención, que conduce a $\mathrm{p} T-\mathrm{p}$, sólo es posible a condición de que $p$ hubiera de cambiar a $-p$, a menos que el cambio lo impida una acción.

$f(-p T-p)=$ abstenerse de suprimir p: esta abstención, que conduce a -pTp, sólo es posible si - $p$ ha de cambiar a p, a menos que el cambio lo impida una acción.

Von Wright exhibe las correspondencias entre las condiciones de la acción, los actos, abstenciones y cambios elementales y sus resultados, en el siguiente esquema:

$\begin{array}{lcc}\begin{array}{l}\text { condición } \\ \text { de la acción }\end{array} & \begin{array}{c}\text { acto o } \\ \text { abstención }\end{array} & \begin{array}{r}\text { resultado } \\ \text { de la acción }\end{array} \\ \text { pT-p } & d(p T p) & p T p \\ p T-p & f(p T p) & p T-p \\ p T p & d(p T-p) & p T-p \\ p T p & f(p T-p) & p T p \\ -p T-p & d(-p T p) & -p T p \\ -p T-p & f(-p T p) & -p T-p \\ -p T p & d(-p T-p) & -p T-p \\ -p T p & f(-p T-p) & -p T p\end{array}$

Por lo que toca a las habilidades de un agente, dice von Wright que aquéllas que recaen sobre actos y abstenciones correspondientes son recíprocas (de manera que si puedo abrir una ventana, puedo abstenerme de abrirla). Pero las habilidades respecto 
de actos y abstenciones de distintos tipos, aunque relativos al mismo estado de cosas, no son recíprocas, sino lógicamente independientes una de otra (que pueda abrir una ventana es independiente de que pueda cerrarla); vale decir, que pueda o no hacer d($p T p)$ es independiente de que pueda hacer o no hacer $d(p T-p)$, y lo mismo vale para $d(-p T p)$ y $d(p T p)$, y para $d(p T-p)$ y $d(-p T-p)$.

Von Wright, a continuación, efectúa un análisis de las normas. Dice que las normas, en las cuales se incluyen órdenes y mandatos, son -la definición es de Alchourrón y Bulygin- sobretodo prescripciones emitidas por uno o varios agentes humanos (llamados autoridad normativa), dirigidas a uno o varios agentes humanos (llamados sujetos normativos), que ordenan, prohiben o permiten determinadas acciones o estados de cosas. Las normas, entonces, tienen seis componentes. Tres de ellos constituyen lo que denomina el 'núcleo normativo': se trata del carácter, el contenido y la condición de aplicación. Los otros tres se predican específicamente de las prescripciones: son la autoridad, el sujeto y la ocasión. Hay, además, un par de 'notas' de las prescripciones que no son propiamente componentes: la promulgación y la sanción -de las que se hablará adelante-. ¿Qué significado tienen estos elementos normativos?:

- el carácter: importa la obligación (o deber $=0$ ), el permiso (o poder $=P$ ) o la prohibición (o tener que no hacer $=0$ ) que establece una norma respecto de una acción o actividad. Por virtud de su carácter, una norma se da con el objeto de que algo deba, pueda o tenga que no ser hecho. Hay que puntualizar algunas cosas. Primero: el mandato positivo y negativo -el deber $(0)$ y el tener que no (0)- son interdefinibles. Segundo: ¿pueden las prescripciones de carácter - $P$ definirse en términos de carácter O? Según von Wright, aquí hay que distinguir dos tipos de permiso, uno fuerte (cuando el estado normativo de un acto ha sido considerado por una autoridad y ésta lo ha permitido sometiéndolo a una norma) y otro débil (cuando un acto no ha sido sometido a una norma y, por esa razón, es posible afirmar que está permitido). Pues bien: solamente el permiso fuerte constituye un carácter independiente de las normas. Este permiso, por lo demás, admite varias especies (de diversa intensidad): el derecho, que es aquella prerrogativa en la cual se combinan un permiso de hacer algo y una prohibición de impedir al titular del permiso hacer dicha cosa; la acción, que es aquella prerrogativa en la cual se combinan un permiso de hacer algo con un mandato de habilitar al titular del permiso a hacer dicha cosa; y la mera tolerancia, que no es más que la no interferencia de la autoridad en -y no la protección de- un acto que el sujeto puedehacer. $Y$ tercero: las normas $-\mathrm{O}$ elementales admiten ocho clases:

$$
\begin{array}{lc}
\text { Od(pTp) } & \text { Od(-pTp) } \\
\text { Of(pTp) } & \text { Of(-pTp) } \\
\text { Od(pT-p) } & \text { Od (-pT-p) } \\
\text { Of(pT-p) } & \text { Of(-pT-p) }
\end{array}
$$

- el contenido: indica la acción (positiva o negativa) o la actividad mandada, permitida o prohibida por una norma.

- la condición de aplicación: alude a aquellas circunstancias que han de cumplirse para que haya oportunidad de realizar el contenido de una norma. Si ' $p$ ' significa que la puerta está cerrada, 'q' que la ventana está abierta y '\&' es la 
conjunción, la expresión 'O (d(-pTp)\&f(qT-q)' contiene las obligaciones de cerrar la puerta y dejar abierta la ventana. Allí, la condición de aplicación de la norma es que la puerta y la ventana estén abiertas y, además, que no se puedan cerrar por sí mismas. Ahora bien: esta condición puede ser categórica o hipotética, según surja del propio contenido (de modo que conociendo el contenido, se conoce por eso mismo la condición de aplicación) o esté expresamente mencionada en la norma misma. Por ejemplo, norma categórica es la que ordena cerrar una ventana, pues en ella se supone la condición de que la ventana esté abierta; y norma hipotética es la que ordena cerrar una ventana 'si' empieza a llover ${ }^{155}$.

- la autoridad: se refiere al agente que dicta la prescripción, que manda, permite o prohibe determinadas acciones o actividades. Por un lado, este agente puede ser supraempírico (es el caso de Dios y las normas teónomas) o simplemente empírico (es lo que ocurre con las normas positivas, sean de agentes personales o impersonales), y por el otro, según si su emisor y su destinatario coinciden o no coinciden, las prescripciones pueden ser autónomas o heterónomas.

- el sujeto: nombra el agente (o los agentes) a quien se dirige la prescripción mandando, permitiendo o prohibiendo ciertas acciones o actividades, esto es, designa al destinatario. La prescripción, en este sentido, puede ser particular o general, según si su destinatario es o bien uno o más individuos humanos específicos o bien todos los seres humanos sin exclusión alguna o todos los hombres que responden a cierta descripción.

- la ocasión: alude a la determinación espacial y temporal dentro de cuyos márgenes la prescripción surte sus efectos. La prescripción es particular si sólo se dicta para una o varias ocasiones específicas, y es general si se da para un número ilimitado de ocasiones, pudiendo dicha generalidad ser conjuntiva (si manda o permite realizar su contenido en todas las ocasiones) o disyuntiva (si manda o permite realizar su contenido en alguna o por lo menos una de las ocasiones). Son pertinentes aquí dos cuestiones. Considerando el sujeto y la ocasión, habría que decir que una prescripción es particular si posee un sujeto y una ocasión particulares, y general si tiene un sujeto general, o una ocasión general, o un sujeto y una ocasión generales (caso, este último, en que la prescripción es eminentemente general). $Y$, en segundo término, cabría preguntarse si las leyes estatales siempre deben ser generales o, más aún. eminentemente generales.

Von Wright trata, enseguida, las relaciones que guardan las normas con el lenguaje y la verdad. Dice que hay dos tipos gramaticales de sentencias de especial importancia para el lenguaje normativo: el modo imperativo y los verbos auxiliares deónticos - debe, puede, tiene que no-. Si, por una parte, el imperativo no siempre se usa para enunciar normas, sino que también se lo utiliza para enunciar plegarias, peticiones y advertencias, por la otra, no todas las normas se formulan por lo común en imperativo, como se ve en las prescripciones permisivas (aunque existen, de todas maneras, los imperativos permisivos). Por lo que toca a los verbos deónticos, von

\footnotetext{
${ }^{155}$ Kalinowski, dicho sea de paso, no sigue en esta materia a von Wright. En efecto, esta distinción entre normas hipotéticas y categóricas (que también hace Kant, claro que con otro alcance) le parece secundaria y prescindible, ya que es posible hacer entrar la condición (sea la de Kant, sea la de Von Wright) o en el nombre del sujeto de acción ('tú que quieres ser feliz, debes hacer esto o lo otro') o en el nombre de la acción ('debes realizar el cerramiento-de-la-ventana-en-el-momento-temporal-t'). Esto se entenderá mejor cuando se aborde el pensamiento de Kalinowski.
} 
Wright extrae las siguientes conclusiones: todas las normas pueden formularse con verbos deónticos, pero no siempre las sentencias deónticas son formulaciones de normas, ya que también pueden enunciar o relaciones anankásticas (o necesarias) o la existencia o vigencia de una norma. Pero, además de las sentencias imperativas y deónticas, cabe expresar normas por medio de sentencias indicativas.

En cuanto al valor veritativo, parece a von Wright que las prescripciones, y otros tipos normativos, carecen de él, lo que no obsta que las formulaciones de normas tengan sentido o significado ${ }^{156}$. Es éste un terreno algo oscuro: las sentencias deónticas son ambiguas, y su uso como formulaciones de normas debe distinguirse de su uso para hacer enunciados normativos, es decir, enunciados sobre la existencia de tales o cuales normas. El fundamento veritativo de un enunciado normativo es la existencia de una norma, y la proposición-norma es aquella proposición que afirma que tal norma existe. Von Wright da el siguiente ejemplo de la ambigüedad señalada. Si yo digo a alguien 'puedes estacionar tu automóvil frente a mi casa', puedo estar dando permiso a mi interlocutor para que estacione su auto frente a mi casa, como también puedo estar informando a mi interlocutor que preguntaba por las normas vigentes en materia de estacionamiento de automóviles.

Ahora bien: si alguien debe, puede o tiene que no hacer algo, es que puede (técnica o realmente) hacerlo. O sea, hay una conexión o implicación lógica entre norma y habilidad, pues toda norma tiene como presupuesto una habilidad para actuar genéricamente (lo que no prejuzga acerca del poder hacer con éxito actos individuales). De lo que resulta claro que 'puede' tiene dos sentidos: uno técnico $(=2)$, referido a la habilidad real, y otro deóntico $(=1)$, constituido por el contenido de una norma permisiva. En una palabra: debe, tiene que no y puede 1 entrañan puede 2.

Continúa von Wright: un agente manda o permite a otro hacer o no hacer una determinada acción porque tal es su deseo, su voluntad: el acto que pone en la

\footnotetext{
${ }^{156}$ Parejamente, Alf Ross afirma en su Lógica de las normas que los directivos carecen del valor de verdad, pues en su opinión no son ni pueden ser verdaderos ni falsos -en la mayoría de los casos, al menos-. Cosa muy distinta es que las proposiciones indicativas que recaen sobre los directivos sí tengan valor de verdad. Surge aquí una dificultad a propósito de los directivos morales y de las normas juridicas sometidas a valoración moral, ya que se discute si es posible conocer unas pretendidas cualidades de validez moral de estos directivos. Empero, esta última cuestión es completamente diversa de aquella otra, de la cuestión del valor de verdad. Así, aun admitiendo factible el conocimiento objetivo del directivo $\mathrm{D}$, de ello no se sigue que $\mathrm{D}$ sea verdadero o falso, puesto que la imposibilidad de atribuir valor de verdad a un directivo resulta directamente de un mero análisis de las nociones de directivo y de valor de verdad. Entonces, la validez del directivo D no coincide con la verdad de la proposición $\mathrm{P}$ que dice que ' $\mathrm{D}$ posee validez objetiva': la verdad sólo incumbe a la proposición. Pero aqui surge una pregunta: ¿tiene significación práctica la distinción entre el directivo $D$ y la proposición $P$ ? ¿No ocurrirá, más bien, que si $P$ es verdadera, necesariamente ha de aceptarse a D como válida? Ante este argumento, Ross ensaya tres respuestas. Primero, dice que esta objeción, aunque fuera sostenible, no desdice la afirmación de que el valor de verdad sólo pertenece a la proposición. Segundo, hay que decir de todos modos que esta objeción contradice el principio de Hume: si no se puede extraer de lo que es, lo que debe ser, tampoco se puede deducir $\mathrm{D}$ a partir de $\mathrm{P}$. $Y$ tercero, si bien puede utilizarse tanto un directivo como una proposición para influir en la conducta de alguien, las funciones de uno y otra son diversas: el directivo tiende a producir directamente un efecto directivo, mientras que la proposición lo tiende a producir tan sólo como un instrumento, es decir, mediatamente (y sobre la base, además, de que despierte el interés o la actitud de ese alguien).

Luego de ello, Ross asegura que la validez de las normas no designa una pretendida propiedad no empírica que se revele a un supuesto conocimiento moral a priori. Designa, en realidad, si un acto jurídico surte o no surte sus efectos jurídicos, de acuerdo a si cumple o no cumple con las condiciones establecidas en las reglas jurídicas, de modo que la decisión jurídica sobre la validez de un acto (que sólo puede hacer un tribunal) no es más que la aplicación de las reglas jurídicas vigentes.

Pese a todo lo dicho, Ross considera posible una lógica deóntica. A su modo de ver, en el discurso normativo operan realmente conectivas lógicas e inferencias, las que si no poseen valor de verdad, si son interpretables por la lógica de otro modo, concretamente por medio de otras tablas valorativas, análogas a las de la lógica ordinaria
} 
existencia a una norma constituye un medio para la realización de los fines que la autoridad normativa se ha propuesto. La teoría voluntarista, pues, parece correcta. Pero hay que reconocer que en el arte de mandar se distinguen distintos grados de generalidad. Si 'a' es la autoridad normativa, 's' el sujeto de la norma y ' $c$ ' el contenido de la norma, es posible diseñar el siguiente cuadro:

\author{
a puede mandar a \\ alguien hacer algo
}

a puede mandar a

alguien hacer $c$

a puede mandar a

s hacer algo

a puede mandar a

s hacer c

\begin{abstract}
s puede ser mandado por
alguien para hacer algo
\end{abstract}

$s$ puede ser mandado por

alguien para hacer $c$

$s$ puede ser mandado por

a para hacer algo

s puede ser mandado por

a para hacer $c$

A continuación, examina von Wright el tema de la existencia de las normas. Dicha existencia no depende sólo de su emisor, sino que depende a la vez de la habilidad del receptor para hacer las cosas. El resultado de la dictación exitosa de una prescripción es la existencia de dicha prescripción y, con ello, el establecimiento de una relación - una vinculación normativa- entre el dador y el receptor de una norma. ¿Y de qué depende ello? Von Wright dice que un acto normativo se ejecuta con éxito cuando la autoridad promulga la norma y le apareja una sanción eficaz. En este acto normativo viene inserta una cierta actividad verbal, que eso es la promulgación. Más concretamente, promulgar consiste en hacer saber a los sujetos de la norma, por medio del lenguaje $u$ otros símbolos, lo que la autoridad normativa desea que hagan, puedan hacer o dejen de hacer. La promulgación es necesaria, mas no suficiente, para que una norma exista. Se requiere, además, una sanción, es decir, una amenaza de castigo explícito o no- ante el evento de la desobediencia, de modo que se acate la prescripción cuando menos por miedo al castigo previsto. La existencia de la norma, claro, pende de la eficacia de la sanción: no tanto de que no sea desobedecida, cuanto de que la desobediencia sea excepcional, anormal, y la eficacia de la sanción, a su vez, depende de la mayor fortaleza de la autoridad en comparación con la de los sujetos. Es en esta eficacia en donde se sustentan las leyes estatales, pues si así no ocurriera, el orden legal se derrumbaría.

Habiendo dado los pasos anteriores, von Wright afirma que sólo con una lógica de las proposiciones (expresiones - $p$ ), una lógica del cambio (expresiones - $T$ ) y una lógica de la acción (expresiones - df) es posible construir una lógica de las normas, una lógica deóntica. La cual, hay que agregar, es un estudio formal de aquellos 
componentes de las normas -sobretodo de las prescripciones- que constituyen el núcleo normativo: o sea, del carácter ( $\mathrm{O}$ y $\mathrm{P})$, el contenido (df) y la condición de aplicación (que, por tener que expresarse en el caso de las normas hipotéticas, requiere de un símbolo especial). Persiste aquí, sin embargo, una ambigüedad ya señalada: las sentencias deónticas expresadas por $\mathrm{O}$ y $\mathrm{P}$ a veces tienen un uso prescriptivo (como formulaciones de normas), pero en otras ocasiones se utilizan descriptivamente (como enunciados normativos o proposiciones-norma). La lógica deóntica, por lo tanto, se vale de la ambigüedad de las expresiones $-O$ y $-P$, por lo que son necesarias dos interpretaciones del mismo simbolismo, una prescriptiva y otra descriptiva. En este punto, y frente a la pregunta de si la lógica de las normas es una teoría de las expresiones - $\mathrm{O}$ y-P interpretadas descriptiva o prescriptivamente, von Wright responde con titubeos: "yo mismo no sé cuál sea la mejor respuesta a esta pregunta. Un sistema 'totalmente desarrollado' de la Lógica Deóntica es una teoría de expresiones descriptivamente interpretadas. Pero las leyes (prncipios, reglas) que son peculiares a esta lógica atañen a propiedades lógicas de las mismas normas, que se reflejan a su vez en las propiedades lógicas de las proposiciones-norma. Así, pues, en cierto sentido, la 'base' de la Lógica Deóntica es una teoría lógica de las expresiones -O y -P prescriptivamente interpretadas".

b) Ahora, me interesa desarrollar algunas de las ideas de la lógica normativa de Georges Kalinowski, tomando en cuenta la Introducción a la lógica juridica, la Lógica del discurso normativo y El problema de la verdad en la moral y en el derecho.

¿Qué lugar ocupa la lógica del lenguaje normativo en el conjunto de la lógica? Si se considera el pensamiento de Aristóteles, dice Kalinowski, se aprecia que el conocimiento discursivo de la realidad puede ser teórico o práctico. $Y$ respecto de los juicios e inferencias teóricos y prácticos, cabe hacer lógica. Hay, así, una lógica teórica y una lógica práctica. $Y$ como hay tres tipos de juicios prácticos: las órdenes, las normas y las estimaciones (o juicios de valor), habrá entonces tres tipos de lógica práctica: lógica de las órdenes, lógica de las normas y lógica de las estimaciones ${ }^{157}$. Kalinowski, como se ve, y como lo han hecho Klug y Millas, distingue las normas de las órdenes, contrariamente a lo que hace von Wright.

\footnotetext{
${ }^{157}$ En este punto puede ser de interés traer a colación las ideas de Klug (tal como aparecen expuestas en la última edición de su Lógica jurídica). A su modo de ver, si la ciencia juridica y la filosofía del derecho pretenden poseer la calidad de ciencias auténticas, no tienen más alternativa que desarrollarse lógicamente. La lógica es necesaria, aunque no suficiente, para ambas disciplinas, lo que no impide, ciertamente, rechazar el logicismo (que es toda inflación exagerada de la lógica). Ahora bien: si la lógica es un instrumento indispensable, ha de utilizársela en su forma más afinada y moderna, valiéndose de la axiomatización y la calculización. Ésta es una verdadera exigencia de la época, y no está vinculada con ninguna postura metafísica o antimetafísica en particular, ya que la lógica no es más que un instrumento.

Klug constata que desde hace mucho tiempo que la ciencia jurídica procede en forma cuasiaxiomática, pues ha venido ocupando un lenguaje cada vez más técnico y preciso. Falta, empero, emprender la difícil tarea de una axiomatización y una calculización más acabadas de los sistemas jurídicos positivos. Como es obvio, este esfuerzo no implica para la jurisprudencia ninguna matematización, o excesiva abstracción, o alejamiento de la vida. En estos afanes, por otra parte, puede resultar muy útil echar mano de la tópica de Viehweg y de la retórica de Perelman, sobretodo para investigar los axiomas juridicos y ponderar su plausibilidad. Mas no debe olvidarse, advierte Klug, que la misma tópica está axiomáticamente vinculada, pues depende de axiomas lógicos y teleológicos.

Teniendo presente lo anterior, Klug define la lógica jurídica como "la teoria de las reglas lógico-formales que llegan a emplearse en la aplicación del derecho ... es, en consecuencia, dentro de la teoría lógica general, la parte especial que se caracteriza por el hecho de ser empleada en la aplicación del derecho". Más concretamente, la lógica jurídica es la teoria de las distintas formas del razonamiento jurídico: de los argumentos por analogía, a contrario, a fortiori, ad absurdum y de los argumentos interpretativos.
} 
Ahora bien: se habla indistintamente de lógica deóntica, lógica de las normas, lógica del derecho, lógica de los juristas, etc. El mismo von Wright ha titubeado: si en 1951 entendió que la lógica deóntica era una lógica acerca de las normas, posteriormente empezó a distinguir entre una lógica de las normas -bastante problemática- y otra de los enunciados sobre las normas -que propiamente es lógica deóntica-. Comoquiera que sea, asegura Kalinowski, no hay que confundir nunca la lógica del derecho, de las normas, con una lógica de los juristas, de los enunciados respecto de las normas. Ya lo han dicho Kelsen y Klug: normas y proposiciones son cosas bien diferentes ¿Qué diferencias hay entre ambos lenguajes? El de los juristas, por supuesto, es bastante más rico que el de las normas. Además, las reglas sintácticas del lenguaje del derecho no autorizan más que la elaboración de expresiones con la estructura de proposiciones normativas que significan normas jurídicas o de proposiciones teóricas sinónimas de aquéllas, mientras que las del lenguaje del jurista admiten proposiciones o metaproposiciones teóricas y permiten la elaboración de proposiciones normativas -que, sin embargo, no son signos de normas jurídicas-.

Kalinowski asume en sus investigaciones las tareas de la semiótica, distinguiendo, pues, la sintáctica, la semántica y la pragmática, partes éstas orgánicamente vinculadas entre sí: una expresión sintácticamente correcta tiene significación, eventualmente verdadera, y es tal para un locutor y para un oyente. Pues bien. En el lenguaje normativo se plantean cuestiones sintácticas (así, hay expresiones correctas e incorrectas), las cuales tienen relevancia práctica (en la interpretación y aplicación del derecho) y teórica (para el conocimiento cabal del derecho). Pero hay también cuestiones pragmáticas: así, la existencia de un derecho (natural) no establecido por el hombre sino por el Legislador Divino y la de otro puesto por los hombres (sea éste oficial o no oficial, escrito o consuetudinario), la validez de las normas (en lo que se plantea, entre otras cosas, la cuestión de la competencia de los órganos y los sujetos para los que las normas valen), el conocimiento y la eficacia social del derecho, lo que se ha entendido por derecho a lo largo de la historia, etc. Y, por fin, existen cuestiones semánticas: ¿cuál es el significado y sentido de las normas y de los términos que las componen?, ¿cuál es su referencia o designación?. ¿son las normas verdaderas por ser válidas, o bien sólo son válidas y no pueden ser verdaderas ni falsas?.

El derecho, dice Kalinowski, es un conjunto de proposiciones, es un sistema. Como tal, posee una serie de propiedades generales, análogas a las propiedades de los sistemas formalizados, como la lógica y las matemáticas. Dichas propiedades son -sin pretender agotar su número- la independencia de los axiomas, la decidibilidad, la coherencia y la completitud. Ellas plantean varias cuestiones, frecuentemente filosóficas. Por ejemplo. ¿Cuáles son las normas jurídicas primeras?, ¿son evidentes y de cantidad precisa?, ¿cómo se las escoge? ¿Qué es lo que decide acerca de la pertenencia -existencia, obligatoriedad- de una proposición normativa al sistema del derecho? ¿Hay coherencia -no contradicción- en el sistema del derecho?, ¿en qué podría ella consistir? ¿Es este sistema completo?, ¿disponen sus normas las consecuencias jurídicas de cualquier hecho?

Kalinowski, a continuación, en su lógica de las normas, distingue tres elementos en una expresión: el enunciado -el signo lingüístico que sintácticamente es una proposición-, el juicio lógico -la significación de la proposición, no el fenómeno psíquico vivido por un hombre, que esto es el juicio psicológico-, y la realidad -el estado de cosas designado por la proposición-. Pues bien: estos mismos elementos están también 
presentes en una expresión normativa (o deóntica): hay allí por una parte una proposición normativa, luego un juicio normativo que no es sino el significado de dicha proposición, y finalmente el estado de cosas designado por esa proposición -que es, in concreto, la relación entre uno o más sujetos de acción y una o más acciones-. Dicho esto, advierte Kalinowski que los enunciados normativos revisten distintas formas gramaticales: el presente o futuro del indicativo ('condena', 'condenará'), el imperativo ('icondena!') y la forma propiamente normativa que le dan los functores creadores de normas ('poder', 'deber', etc.). (Inversamente, el juicio teórico no puede tener -en propiedad- la forma de un enunciado normativo. $Y$ respecto del juicio imperativo, hay que distinguir. El juicio propiamente imperativo -la orden- no admite ni una expresión indicativa ni una normativa. Pero el imperativo por metonimia (o por figura retórica) sí puede expresarse por manera normativa, ya que es verdaderamente una norma, no una orden). Por esta razón no es posible distinguir los enunciados normativos de aquéllos que no lo son recurriendo a la pura forma gramatical. Por lo tanto, la distinción de la categoría semántica requerirá, además, de la identificación del contexto en el cual aparecen dichos enunciados. Decir, empero, como se ha hecho, y aunque lo que recién se ha dicho sea cierto, que las normas no pueden ser definidas recurriendo a la sintaxis de sus enunciados, es una exageración. Puesto que las normas, si bien admiten diversas formas gramaticales como medio de expresión, tienen una estructura proposicional propia, una forma lingüística que les pertenece en tanto que normas independientemente de la mayor o menor ocurrencia estadística de esta forma-. ¿Cuál es esta categoría de enunciados que propiamente pertenece a las normas? Es aquella forma auxiliada por los verbos 'deber' o 'poder', con o sin negación antecedente o subsiguiente. Todas las normas, y sólo las normas, pueden ser expresadas por medio de estas proposiciones propiamente normativas. $Y$ las normas, debe agregarse, son siempre categóricas, ya que establecen una obligación cuya fuerza obligatoria no depende del sujeto al cual se dirigen; una norma moral (que eso es una norma jurídica, según Kalinowski, como se verá) nunca será hipotética en este sentido, al margen de que sintácticamente pueda revestir una forma condicional.

Según Kalinowski, sintácticamente, la proposición normativa designa un estado de cosas que es una relación, la que consta de tres elementos: un nombre (individual o general) de sujeto de acción, un nombre (individual o general) de acción y un functor proposicional normativo o deóntico (que es el que da origen a la proposición normativa). Estos functores fueron en un comienzo cinco: obligación de hacer ('debe hacer' $=$ 'S'), obligación de no hacer ('debe no hacer' $=$ 'L'), permisión unilateral de hacer ('tiene derecho a hacer' $=^{\prime} P^{\prime}$ ), permisión unilateral de no hacer ('tiene derecho a no hacer' $=$ ' $W$ ') y permisión bilateral de hacer o no hacer ('tiene derecho a hacer y tiene derecho a no hacer' $=$ ' $M$ '). Luego, al tener en cuenta la lista exhaustiva de las relaciones de oposición de los hexágonos de Sesmat y Blanché, Kalinowski añadió un sexto functor: obligación de hacer o de no hacer ('debe hacer o debe no hacer' $=$ ' $V$ '). Los functores, como se ve, son verbos. Pero desde el punto de vista de la lógica tal cosa no importa, como tampoco las formas gramaticales de estos verbos, sus conjugaciones activa o pasiva, sus modos, tiempos, persona y número: en lógica simbólica todo esto no interesa. Muy sencillamente, cabría representar la sintaxis de una norma del siguiente modo: $R \times a$, que significa: ' $x$ está en la relación $\mathrm{R}$ con a'. $\mathrm{O}$, con algo más de concreción, como sigue: Sxa, que significa: 'el o los sujetos de acción x está está en relación de obligación de hacer respecto de la o las acciones a', o 'x debe hacer a'; Lxa...; Pxa...; Wxa ...; Mxa...; Vxa... Ahora bien: ' $x$ ' es una variable nominal individual 
que puede ser reemplazada por un nombre individual -es la individualización-, por un cuantificador existencial -es la particularización- o por un cuantificador universal -es la universalización-. De manera que, habiendo tres tipos de nombres de sujetos de acción y otros tres tipos de acciones, son posibles nueve clases de proposiciones normativas. Enseguida, estas proposiciones normativas admiten cuatro tipos de negaciones: la de la norma o proposición normativa, la del functor, la del nombre del sujeto de acción y la del nombre de la acción. Cada una de estas negaciones presenta sus peculiaridades. Por ejemplo: si se considera que las acciones pueden ser buenas, indiferentes o malas, la negación de cada una de ellas acarreará consecuencias muy distintas: así, de la negación de una acción buena resultará una acción mala, y viceversa, y de la negación de una acción indiferente no saldrá más que otra acción indiferente.

Ahora bien: ¿es cierto que los imperativos no son verdaderos ni falsos? Si por imperativo se entiende la orden, es indudable que allí no hay verdad ni falsedad (como tampoco en las interrogaciones y exclamaciones). Pero si el imperativo se refiere a la norma, la conclusión de Kalinowski es justamente la contraria: las normas son verdaderas o falsas -inversamente de lo que muchos pretenden, como von Wright y Ross-. Teniendo en cuenta que las normas morales incluyen las normas morales en sentido restringido (o ley natural), las normas jurídicas en sentido restringido (o ley humana) y las reglas de conciencia, la aseveración de Kalinowski es que todas las normas morales son verdaderas o falsas, siguiendo en esto la caracterización clásica de la verdad y la definición de Tarski. Así, la definición de la proposición verdadera: la proposición ' $p$ ' es verdadera si y sólo si p, puede reemplazarse por esta expresión: 'Carlos debe pagar su deuda' es verdadera si y sólo si Carlos debe pagar su deuda. Aquí interesa, en particular, el parecer de Kalinowski respecto de las normas jurídicas en sentido restringido, aunque no está de más consignar que, para él, la verdad de la ley natural radica en su concordancia con la ley eterna. Este autor distingue entre aquellas normas jurídicas que tienen el carácter de conclusión o aplicación de la ley natural, y aquellas normas que están sobrepuestas a las conclusiones de la ley natural (o normascomplemento). Respecto de las primeras, obligan y son verdaderas por su concordancia con la ley natural, es decir, en virtud de la obligatoriedad y verdad de la ley natural de la que son conclusión o aplicación. En cuanto a las normas jurídicas del segundo tipo, más lejanas de la ley natural, también son verdaderas por su conformidad o adecuación con la ley natural. Así, es posible afirmar que la norma según la cual se debe circular por la derecha arranca en último término de la ley natural, puesto que ésta obliga en general a hacer lo que favorece -y no lo que perjudica- al bien común y a la vida social, de manera que si en un lugar y época determinados resulta riesgoso no regular la circulación, el legislador humano deberá disponer algunas reglas por las que se rija el tráfico circulatorio, una de las cuales tendrá que señalar, alternativamente, que habrá de circularse por la derecha o por la izquierda (lo que constituye una aplicación del modus tollendo ponens) ${ }^{158}$.

${ }^{158}$ Conviene, una vez más, recordar aquí el pensamiento de Klug con alguna morosidad. Cabe, según este autor alemán, realizar una axiomatización del derecho positivo, claro que teniendo en cuenta que los sistemas jurídico-positivos pueden ser sólo relativos (por lo cual siempre es posible reemplazar un sistema de axiomas por otro), respetando por cierto las reglas del método axiomático (es decir, procurando que los axiomas elegidos no se contradigan unos a otros y que ellos sean suficientes para deducir los enunciados jurídicos que se desean) y sometiendo la corrección final de todo acto legislativo-positivo (o sea, de todo axioma jurídico) a un vínculo teleológico (o sea, a un axioma teleológico), tarea esta última que incumbe a la filosofía del derecho (y que han emprendido, entre muchos otros, Wolff, Stammler y Emge). Para Klug, la tarea de la lógica ha de ser 
Empero, ¿es posible la justificación racional de la verdad de las normas?. Kalinowski dice que sí. El sistema normativo, como todo sistema, posee reglas de admisión según las cuales tal o cual proposición se considera parte suya o extraña a él. Pues bien. Hablando en general, existen proposiciones primeras, cuya admisión en un sistema no depende de otras proposiciones, sino que reposa en su evidencia empírica o analítica o en una convención; y hay, además, proposiciones segundas, que integran un sistema en dependencia de otras proposiciones, en virtud de un raciocinio, una demostración, una inferencia de la que son conclusión. En el caso del sistema normativo, las proposiciones normativas primeras (por ejemplo, 'se debe hacer el bien y

apoyada por la teleologia, tal como la teleología debe apoyarse en la lógica. Incumbe a la filosofía del derecho y a la ética filosófica proponer sistemas de axiomas teleológicos, vinculantes para los sistemas axiomáticos del derecho positivo y contralores -de manera hipotética y aproximativa- de cualquier comportamiento humano. El mismo establecimiento de cálculos lógicos tiene que estar teleológicamente vinculado. Mas, de otra parte, un sistema de axiomas teleológicos debe diseñarse de acuerdo a las reglas de la lógica y, también, cualquiera deducción de teoremas teleológicos a partir de axiomas teleológicos ha de ceñirse al cálculo lógico. Comoquiera que sea, admite Klug, la exacta relación entre lógica y teleología es aún un problema abierto. $Y$ aunque Klug acepta que los axiomas son siempre convencionales, piensa que el relativismo ilimitado es insostenible y, en último término, se anula a sí mismo. Por ello, prefiere sostener que los axiomas tienen siempre un carácter hipotético y, por lo mismo, que es más adecuado tomar en estas materias una actitud escéptica y no relativista.

Ahora bien: Klug afirma que "en la construcción de los sistemas teleológicos no aparecen peculiaridades desde el punto de vista formal, puesto que no hace falta introducir nuevos simbolos lógıcos", y que conceptos como los de adecuación de una norma o de una conducta, rectitud de una ley, etc. "pueden traducirse sin dificultad en fórmulas del cálculo de predicados". Klug muestra algunos ejemplos de modelos de axiomas teleológicos:

(18.1) $\quad(x)(V A(x)-Z W(x))$

$(18,2)(x)\{[(x)(V A(x)-Z W(x))]-[(x)(V A(x)-G B(x))]\}$

$(18.3) \quad(x)(\operatorname{VA}(x)-G B(x))$

$(18,4) \quad(x)($ VA $(x)-S O(x))$

¿Cómo pueden leerse estos axiomas? (18.1) "para todo $x$ vale siempre que $\times$ sea una conducta $A$, $x$ entonces serà adecuada" (18.2) -ampliación de (18.1) -: "siempre que una conductá VA sea adecuada, la conducta VA estará entonces prescrita". (18.3) -inferencia deducida a partir de (18.1) y (18.2) - "la conducta VA está prescrita". (18.4)-donde se identifica estar prescrito y ser debido- "la conducta VA es una conducta debida". La legitimidad sintáctica de las determinaciones y deducciones anteriores le parece a Klug irrefutable. Y en perspectiva semántica, (18.1) y (18.2) son axiomas, o sea, fórmulas verdaderas, por lo cual (18.3) es una deducción verdadera. Además, (18.3) y (18.4) son interpretables como formalizaciones de una norma juridica.

De lo anterior, asegura Klug, es posible hacerse una idea de los problemas con los que se encuentra la lógica de las normas (entre cuyos cultores se menciona a Mally, von Wright. Hilpinen, Kalinowski, von Kutschera, Stegmüller, Tammelo, Weinberger, Ziemba, Ziembinski). La lógica deóntica comenzó por creer que las normas no son traducibles como proposiciones aptas para los cálculos proposicionales y de predicados corrientes, ya que la norma no sería ni verdadera ni falsa. Empero, según Klug "es fácil darse cuenta de que tanto las normas generales como también las individuales se formulan por el respectivo órgano emisor de normas -legislador o juez-como enunciados que dicen que es verdadero o falso que algo está mandado, prohibido o permitido. Naturalmente, la verificación no resulta de que, por ejemplo, se establezca empiricamente si de hecho la respectiva norma ha sido obedecida. Porque... sigue siendo verdad que el demandado que fue condenado [a pagar] tiene la obligación de pagar, aunque él no lo haga... Para prevenir equivocos, digamos lo siguiente: falsa [o verdadera] no es aquí una proposición sobre una norma individual, sino esta norma misma... Las consideraciones anteriores... muestran cómo tiene pleno sentido preguntar por la verdad de las normas, y que la traducción de normas por medio de expresiones de los cálculos de proposiciones, de predicados, de clases o de relaciones no tropieza con dificultades de principio".

La cuestión de la verdad de las normas, pues, es perfectamente legitima. Y ello se funda en el concepto de proposición verdadera expuesto por Tarski ( $y$ adoptado, entre otros, por el mismo Kalinowski). Por lo demás, Klug constata que en la práctica juridica alemana frecuentemente se supone que las normas son verdaderas o falsas (asi, es muy común que una sentencia se denomine 'veredicto').

Sin embargo, advierte Klug, no hay que olvidar que la lógica está menos basada en el concepto de verdad que en el de consecuencia. La lógica, como han dicho varios autores, es sobretodo la teoria de la consecuencia. Esta afirmación abona en favor de la aplicabilidad de los cálculos proposicionales, de predicados, de clases y de relaciones con el objeto de efectuar un control lógico de las deducciones en el ámbito de las normas. 
evitar el mal', 'todo hombre debe respetar su vida y su salud', 'todo hombre debe vivir en sociedad no solamente familiar sino también política', etc.) se admiten, no por convención (como ocurre en lógica y matemáticas), ni tampoco por evidencia empírica (ya que ésta capta objetos singulares a partir de la percepción, mientras que las normas primeras son universales), sino por evidencia analítica. Las normas primeras son analíticamente evidentes, ya que del mero análisis de las realidades que ellas designan se desprende su concordancia con la realidad. A ellas no se arriba por inferencia alguna. Por el contrario, las proposiciones normativas secundarias se admiten en el sistema normativo por causa de una inferencia deductiva que parte de una norma primera analíticamente evidente. La verificación de las normas segundas, por lo tanto, requiere de la verdad material de sus premisas y de la corrección de los raciocinios deductivos. Esta verificación, pues, supone una silogística normativa.

Massini ha intentado resumir estas -y algunas otras- ideas de Kalinowski respecto de la significación y designación de los enunciados normativos. Por lo que respecta al sentido o significado, dice lo siguiente: "i) las expresiones lingüísticas de carácter normativo no son en sí mismas normas, sino sólo el signo, el significans de normas morales o jurídicas; ii) las normas consisten en proposiciones de carácter normativo, resultado de juicios también normativos, esto último en razón de su función también directiva o reguladora del obrar humano: iii) la estructura de esa proposición en que la norma consiste, une el nombre de un sujeto de acción, con el nombre de una acción a través de un functor normativo; éste puede ser alguno de los siguientes: 'debe hacer', 'debe no hacer', 'tiene el derecho de hacer', 'tiene el derecho de no hacer', 'puede hacer o no hacer' y 'debe hacer o debe no hacer'; iv) la norma no se confunde con el juicio normativo, acto psicológico individual que le da origen, sino que tiene una existencia puramente 'intencional', es decir, de razón; v) entre los posibles entes intencionales, las normas consisten en entes intencionales cognoscitivos, es decir, referidos a ciertos objetos de conocimiento, razón por la cual pueden ser calificadas de verdaderas o falsas". En cuanto a la referencia de los enunciados normativos, o sea, a la relación de las expresiones con ciertos entes o estados de cosas en Kalinowski, Massini dice: "las normas cumplen la función semántica de designación y lo hacen designando relaciones deónticas existentes en la realidad, aunque sea de modo simplemente posible; estas relaciones se establecen entre sujetos de acción y clases de acciones -en el caso de las normas generales- y obtienen su deonticidad de dos fuentes: en ciertos casos de la adecuación o inadecuación entre el modo de ser del hombre y el valor o disvalor de las acciones y en otros de la decisión del legislador entre alternativas de acción, en situaciones en las que resulta deónticamente necesario reglar un tipo de conducta humana. Esta designación de las normas es una designación en sentido formal o 'fuerte', todas vez que no se designan relaciones meramente 'de razón', sino relaciones reales, existentes con independencia de que las pensemos actualmente". Para terminar, Massini afirma: "las conclusiones de la semántica normativa kalinowskiana: i) que los enunciados normativos no son el signo sólo de entidades mentales, sino que también -y principalmente- remiten a estructuras de la realidad; ii) que la semántica normativa no puede acotarse a la mera significación, sino que es necesario trascenderla hacia la designación de las normas; iii) que esta designación tiene como designatum a relaciones deónticas reales, existentes de modo objetivo, trascendentes a la interioridad de los sujetos, conducen, por la vía del lenguaje, a la afirmación que rescataba 
Spaemann: que en última instancia, lo justo y lo injusto no dependen de la inmanencia humana, sino que arraigan en estructuras reales objetivas trascendentes al sujeto".

Kalinowski construye dos sistemas lógicos ( $K 1$ y $K 2$ 2) bajo la forma de un cálculo relacional. En uno de ellos utiliza las leyes de oposición de las proposiciones y la teoría de las proposiciones modales, pues observa una analogía entre las proposiciones normativas y las proposiciones modales; y en el otro, las leyes de la silogística asertórica y modal, efectuando -en buena medida- una axiomatización de los silogismos prácticos de Aristóteles. En aquél, Kalinowski llega a representar las oposiciones de las proposiciones normativas, primero, por medio de una pirámide lógica, y después, siguiendo a Blanché, a través de un hexágono. Y en éste, Kalinowski arriba a un elevado número de leyes de la silogística normativa.

Por fin, dice Kalinowski que la lógica deóntica se encuentra aún en sus comienzos, en faena de pleno análisis; que su construcción es una obra colectiva en la que cada autor está haciendo su contribución; que, de todos modos, la más importante e influyente de las contribuciones en este campo es la de von Wright; y que esta lógica ha tenido un rápido desarrollo y ha conocido el empleo de las técnicas lógicas más dispares.

Por lo que toca al lenguaje jurídico o de los juristas, Kalinowski señala un elenco de raciocinios jurídicos. Primero, distingue raciocinios de coacción intelectual (pertenecientes a la lógica formal en sentido propio), raciocinios de persuasión (de los que se ocupa la retórica) y raciocinios extralógicos (como la argumentación puramente jurídica, basada en presunciones, ficciones, prescripciones, etc.). Kalinowski, como se ve, acepta que la lógica formal no agota el tratamiento lógico del discurso de los juristas y que se precisa por lo tanto de la retórica, la tópica, la dialéctica, etc. -sobre las cuales habrá que volver-; empero, lo que no admite es que la lógica estricta o formal no tenga papel alguno en la consideración de los raciocinios jurídicos. Así divididos, Kalinowski se concentra solamente en los razonamientos jurídicos de coacción intelectual, que son los raciocinios lógicos por excelencia. Tales razonamientos, dice Kalinowski, pueden ser normativos (si en ellos hay proposiciones normativas que desempeñan el papel de la o las premisas y de la conclusión) y no-normativos (los cuales sólo son jurídicos por accidente, o sea, por causa de su contenido o de la persona que los ejecuta). Los raciocinios jurídicos no-normativos, cuya conclusión es en algunos de ellos cierta y en otros solamente probable, son los siguientes:

$1^{\circ}$ la inducción completa: es aquel raciocinio que lleva a admitir, sea por verificación empírica o de otra clase, la verdad de una proposición universal ('todo S es $\mathrm{P}^{\prime}$ ) si se ha reconocido antes la verdad de ciertas proposiciones singulares ('S 1 es P', 'S 2 es $\mathrm{P}^{\prime}, \ldots$. 'S $\mathrm{n}$ es $\mathrm{P}^{\prime}$ ') y si se ha admitido la verdad de la proposición en cuya virtud se establece una equivalencia entre la suma de diversos nombres individuales y el nombre general ('si la especie P no contiene más individuos que $S 1, S 2, \ldots$. n').

$2^{\circ}$ el raciocinio deductivo: es aquel raciocinio en el que el paso de la o las premisas a la conclusión se rige por una regla que está asegurada por alguna ley lógica, de modo que la conclusión será verdadera si su o sus premisas son verdaderas, y sólo probable, si éstas son sólo probables.

$3^{\circ}$ el raciocinio reductivo: es aquel raciocinio cuya premisa incluye un efecto, respecto del cual la conclusión señala la causa, sea ésta solamente probable, sea cierta 
(cosa que ocurre cuando un efecto no puede ser producido más que por una determinada causa).

$4^{\circ}$ el raciocinio por analogía: es aquel raciocinio que tiene por premisa $\circ$ premisas a una o más proposiciones singulares que se refieren a objetos pertenecientes a una determinada especie, y que tiene por conclusión -probable- a una proposición singular que se refiere a un objeto esencialmente semejante a los objetos de las premisas.

$5^{\circ}$ la inducción incompleta o amplificante: es aquel raciocinio cuyas premisas son proposiciones singulares ciertas, que se refieren a objetos concretos de igual especie, y cuya conclusión es una proposición universal, en principio probable $-y$, por excepción, cierta-, que extiende a toda la especie la afirmación (o negación) de las premisas, dándose el paso de aquéllas a ésta por razón de que el carácter de la propiedad (o de la falta de ella) comprobada en las premisas sería esencial a toda la especie,

$6^{2}$ el raciocinio estadístico; es aquel raciocinio que tiene varias premisas singulares ciertas, referidas a objetos de igual especie, algunas de las cuales reconocen en sus objetos un atributo, mientras que las demás se los niegan a los suyos, raciocinio en el cual la conclusión es singular, pues se refiere a un objeto de igual especie que la de las premisas, y sólo probable, aunque en un grado bien determinado-de acuerdo a las reglas del cálculo estadístico-.

$7^{\circ}$ la justificación jurídica racional: es aquel raciocinio que procura mostrar la evidencia -empírica $\circ$ analítica- de una proposición, o que trata de probarla racionalmente:

- una proposición es evidente de manera empírica cuando el intelecto, a través del sentir, capta su concordancia con la realidad;

- una proposición es evidente de modo analítico cuando del análisis de los objetos que son el sujeto y el predicado de dicha proposición resulta que el predicado es el definiens, o una parte de él, o una propiedad esencial implicada en él, o cuando el propio sujeto es un elemento de la definición del predicado;

- una proposición está racionalmente probada, por una parte, a través de cualquiera de los raciocinios ya examinados que otorgan una prueba directa, o a través de raciocinios que sólo proporcionan pruebas indirectas (es el caso de la reducción por el absurdo, de la eliminación etc.), y desde otro punto de vista, por intermedio de las 'pruebas metodológicas', de los argumentos retóricos de persuasión y de las pruebas estrictamente jurídicas.

En segundo término, los raciocinios jurídicos normativos, siempre deductivos, que intervienen en la elaboración, interpretación y aplicación del derecho, y que se rigen por las reglas de la lógica de las normas, son los siguientes:

$1^{\circ}$ Las reglas presentes en la elaboración del derecho: si el derecho es una regla de conducta racional, entonces toda norma habrá de estar racionalmente justificada. Los medios de tal justificación son análogos a los medios que se utilizan en los raciocinios jurídicos no-normativos. Hay, pues, normas jurídicas evidentes (analíticamente, por supuesto) y normas, si bien no evidentes, cuya justificación racional descansa en una prueba, la cual puede ser procurada por la lógica (es el caso 
de los raciocinios deductivos deónticos, que obedecen a reglas garantizadas por las leyes de la lógica deóntica, y que son, o las leyes de la oposición de las proposiciones normativas, o las leyes de la silogística normativa) o por el derecho (es el caso de las normas cuya validez depende de que hayan sido dictadas por un sujeto que, en virtud de otra norma, sea titular de un poder legislativo).

$2^{2}$ Las reglas presentes en la interpretación del derecho: al momento de interpretar el derecho, cualquier intérprete utiliza reglas lógicas (o de coacción intelectual), extralógicas (o retóricas) y paralógicas (o meramente jurídicas) de raciocinio. Esto es claro en los diversos argumentos de corriente utilización en la vida jurídica. Así, son extralógicos los argumentos a rubrica, de los trabajos preparatorios y pro subjecta materia; paralógicos, los argumentos ab auctoritate, a generali sensu y ratione legis stricta; y lógicos, los argumentos a fortiori ratione (sean a maiori ad minus, sean a minori ad maius), a pari (a simili) ratione y a contario sensu. Kalinowski se interesa sobretodo por los argumentos lógicos, aunque reconociendo, como no puede ser menos, que éstos están sometidos tarito a leyes de la lógica deóntica cuanto a reglas puramente jurídicas, reglas que, por un lado, son dictadas por la prudencia del legislador o, supletivamente, por la del intérprete, teniendo en cuenta en ambos casos la naturaleza de las cosas, y por el otro, permiten sobreentender en el texto interpretado las cláusulas que hacen posible la aplicación de los distintos argumentos:

$3^{\circ}$ Las reglas presentes en la aplicación del derecho: los raciocinios jurídicos normativos, también necesarios en esta etapa (pese a que no la agoten), son los silogismos jurídicos, necesarios tanto si la norma a aplicar es general como si es individual. Si la norma a aplicar no es condicional, entonces el silogismo jurídico es categórico, y si es condicional, el silogismo será hipotético. La forma del silogismo categórico es ésta: toda persona que hace $X$, debe ser castigada; una persona hace $X$; luego, debe ser castigada. Y la del silogismo hipotético es ésta: si $\mathrm{H}$ tiene lugar, entonces $\mathrm{S}$ debe tener lugar; $\mathrm{H}$ tiene lugar; luego, $\mathrm{S}$ debe tener lugar. De todos modos, la utilización del silogismo jurídico plantea problemas, por cuanto no es fácil ponerse de acuerdo ni sobre las normas ni acerca de los hechos en cuestión.

\section{La vía de la lógica razonable}

También en los años 50, curiosamente, principiaron los estudios de la tópica y de la nueva retórica argumentativa. $Y$, con ellos, se abrió el camino para la formación de una lógica normativa ya no estricta y formal, sino más bien tópica, argumentativa, hermenéutica, dialéctica, en general razonable. Ahora bien: en este camino hay quienes pretenden (como Perelman) que el mundo de las normas morales y jurídicas tiene una lógica propia -práctica e informal- que no admite de ningún modo una lógica ceñida y abundante en silogismos, y hay también los que creen (como Klug y Kalinowski) que para las disciplinas normativas ha de contarse con los servicios de una y de otra. Presento, ahora, brevemente, a algunos cultores de la lógica razonable.

a) En primer lugar Viehweg. Tanto en Tópica y jurisprudencia como en otros trabajos posteriores, este autor ha destacado que el pensamiento jurídico es un pensamiento problemático y que la jurisprudencia no puede ser desconectada de la tópica, una de las técnicas de este tipo de pensamiento que fue desarrollada por la retórica. A su modo de ver, la jurisprudencia no es susceptible de una exacta 
sistematización deductiva, ya que no es más que un procedimiento especial para la discusión de problemas, el cual -por supuesto- ha de perfilarse de manera clara y según su naturaleza. ¿Cómo?

Viehweg comienza con una alusión a Vico. En 1708, dice, Gian Battista Vico elaboró una dissertatio titulada De nostri temporis studiorum ratione. En ella, Vico alude a los scientiarum instrumenta -a los métodos científicos-, diciendo que el antiguo método, transmitido por Cicerón, era retórico (o tópico), y que el nuevo, indudablemente cartesiano, es crítico. Mientras el nuevo método crítico parte de un primum verum, indubitable, que se desarrolla según la manera geométrica a través de largas deducciones encadenadas, la antigua tópica tiene como punto de partida al sensus communis, afincado en lo verosímil, en diversos puntos de vista y en un tejido de silogismos. Y si el nuevo método es muy agudo y preciso, la vieja retórica, a su turno, posee una singular penetración, desarrolla la fantasía y la retentiva y facilita el examen de las cosas desde diversos ángulos y puntos de vista. Por todo ello, concluye Vico, debe incardinarse el viejo método en el nuevo, pues la moderna crítica no tendrá efectividad alguna sin el concurso de la tópica.

Pues bien: dos momentos fundamentales de la tópica, asegura Viehweg, se viven con Aristóteles y con Cicerón. En la Tópica -y también en los Argumentos sofísticos-, que es parte del Organon. Aristóteles estudia el viejo arte de disputar y busca una teoría filosófica de los tópicos. Aristóteles, en efecto, distingue un ámbito de lo apodíctico, propio de la verdad filosófica, y un ámbito de lo dialéctico, propio de las opiniones de retóricos y sofistas y en el que se ubica la tópica. Ahora bien: las conclusiones dialécticas son aquéllas a las que se arriba a partir de pareceres verosímiles, aceptables y acreditados, es decir, de simples opiniones, sean éstas aceptadas por todos, por la mayoría o por los sabios y, entre éstos, por todos, por la mayoría o por los más famosos, razón por la cual estas conclusiones se distinguen de las demás tan sólo por la índole de sus premisas. Los tópicos (tópoi) se refieren a las conclusiones dialécticas y retóricas, y pueden ser clasificados muy diversamente. Por su parte, la Tópica de Cicerón fue a la vez menos teórica y más influyente que la de Aristóteles, pretendió ser una verdadera guía práctica de la argumentación y fue escrita a pedido de un jurista amigo del autor. Según Cicerón, la teoría de la disertación ha de considerar la invención -la tópica- y la formación del juicio -la lógica-. Mas, ¿qué son los tópicos? Según Cicerón, son los lugares de donde se extrae el material para la demostración. Y pueden ser clasificados de muchas maneras, siempre teniendo en la mira un interés práctico. En fin: tópica y retórica preexistían a Aristóteles y sobrevivieron a Cicerón, como parte de la formación educativa antigua y medieval.

¿Qué decir, más analíticamente, de la tópica?, se pregunta Viehweg. Tanto en Aristóteles como en Cicerón, la tópica es una técnica del pensamiento problemático (y no del pensamiento sistemático), es, por lo tanto, el arte de la invención (ars inveniendi), de la discusión de los problemas, el arte de considerar en cada situación las razones, a favor y en contra, que aconsejan y que desaconsejan dar un cierto paso, el arte, pues, no del reflejo sino de la reflexión. La tópica es una técnica para la búsqueda de premisas, de material para ponerse a pensar. En este sentido, la tópica es un pensar pre-lógico, ya que la tarea de la inventio es la primaria y la de la conclussio, secundaria: aquélla busca las premisas y ésta trabaja con ellas. Siendo así, las premisas tópicas necesitan de la aceptación, de la aprobación del interlocutor en el marco de un debate razonable, pudiendo aspirarse con ella a una adecuada intelección, y no a puras 
opiniones antojadizas. De todos modos, existen conexiones entre problema y sistema. Problema, dice Viehweg, es "toda cuestión que aparentemente permite más de una respuesta y que requiere necesariamente un entendimiento preliminar, conforme al cual toma el cariz de cuestión que hay que tomar en serio y a la que hay que buscar una única respuesta como solución". Bien formulado, el problema da lugar a un conjunto de deducciones más o menos explícitas y extensas, luego de las cuales se consigue una solución. Si a este conjunto de deducciones se lo llama sistema, resulta que el hallazgo de una solución requiere de la incardinación del problema en un sistema. Empero, aunque problema y sistema estén conectados, no da lo mismo partir de uno o de otro, ya que si se coloca el acento en el sistema se producirá de inmediato una selección de los problemas a considerar, y viceversa. Además, un pensar sistemático, premunido de pocas y muy constantes premisas, permite largas conclusiones en cadena; un pensar tópico, en cambio, sólo admite conclusiones cortas, en constante vinculación con el problema y, con frecuencia, analógicas. El sistema permite una demostración estrictamente racional de sus proposiciones; la tópica, al contrario, no opera más que con proposiciones discutibles. Ahora bien: se puede advertir una tópica de primer grado, propia de la vida diaria, en la que se escogen arbitrariamente unos puntos de vista ocasionales, que se estiman como premisas adecuadas para la obtención de consecuencias. $Y$ hay una tópica de segundo grado, verdadero remedio para la inseguridad de la de primer grado, que se sirve de catálogos -relativamente elásticos- de puntos de vista preparados con antelación. Por otra parte, pueden reconocerse tópicos de aplicación universal y tópicos restringidos a ciertas ramas del saber.

¿Qué relevancia ha tenido la tópica en la historia del pensamiento jurídico? Viehweg aborda algunos episodios a título ejemplar, partiendo por el ius civile. Éste, como es claro, es bastante asistemático y no permite largas series de deducciones. Hay en él nexos, pero de carácter problemático, pues su proceder es muy casuístico y práctico y las soluciones de los problemas lo fuerzan a recurrir a multitud de puntos de vista. Viehweg cita la decidora caracterización que hace Savigny de la jurisprudencia romana: "es como si un caso cualquiera fuera el punto de arranque de toda la ciencia". El derecho es una construcción dialéctica de los juristas de Roma. Las fijaciones del derecho escasean, y una vez producidas, dan lugar a una abundante interpretación. Existen colecciones de puntos de vista, de tópicos, de reglas jurisprudenciales sin propósitos sistemáticos, con frecuencia sin orden y en las que se recurre mucho al argumento de la autoridad de hombres notables. Por todo ello, el ius civile se asemeja a lo que Aristóteles entendió por tékhne. En Roma, los juristas y los retóricos tuvieron la misma actitud, y los vínculos de aquéllos con el método de los filósofos se refieren sobretodo a la dialéctica aristotélica, que no a la estoica (por cierto, estrictamente lógica).

Continúa Viehweg con el mos italicus, que fue, con seguridad, tópico y problemático. Así lo demuestra la propia formación de glosadores y comentaristas, que da cuenta de una estrecha convivencia entre retórica y jurisprudencia. La jurisprudencia medieval fue interpretadora, exegética: algunos de sus problemas fueron el de la contradicción de los textos y el del establecimiento de correlaciones adecuadas que justificaran la aplicación de un texto. La misma forma escolástica tiene un evidente sello tópico: así se aprecia en Tomás de Aquino, en Bartolo, etc. El espíritu escolástico no es deductivo, sino que se apresta siempre para la discusión de problemas. Incluso las 
generalizaciones (generalia) constituyen más bien ejemplos de catálogos de tópicos construidos a partir de problemas concretos y cuyo uso era recomendado a los alumnos.

Ars combinatoria es el siguiente hito examinado por Viehweg. La jurisprudencia, dice, no es un método riguroso, unívoco y deductivo, sino un estilo bastante amorfo y poco comprobable: de esta opinión parece haber sido el joven Leibniz en su Dissertatio de arte combinatoria. Allí considera de manera combinatoria a la jurisprudencia, y no de modo deductivo o sistemático; intenta aprovechar el estilo intelectual del medioevo y el matematismo del siglo XVII a través de una matematización de la tópica y, más en concreto, de una casuística jurídica general. Leibniz, de todos modos, fracasó en este intento y posteriormente siguió otros derroteros que lo llevaron a la axiomatización del derecho. Es lo que, a continuación, estudia Viehweg.

Frente a un estilo de pensamiento, caben dos posibilidades. Una: convertirlo, transformarlo en una reflexión deductiva y sistemática. Otra: conservarlo como tal y, de este modo, convertirlo en objeto de una ciencia. En el caso de la jurisprudencia, esto significa o bien una sistematización del saber jurídico mismo o bien el hacer objeto de ciencia metódica un saber que en sí no es ni puede ser metódico ni sistemático. Pues bien: la cultura moderna pretende precisamente una axiomatización -incluso una formalización- de la jurisprudencia, su conversión en una ciencia estricta, sustituyendo su impronta tópica por un carácter sistemático. Esta empresa, sin embargo, es imposible. Si se conservara algo de lenguaje espontáneo, allí habría tópica; si se construyera un sistema jurídico absolutamente formalizado, a la hora de su aplicación real requeriría de un precepto de significación (esto es, de referencia a la realidad), que lógicamente no puede ser sino arbitrario; si continuara presente en alguna medida la faena de la interpretación (sea para eliminar las colisiones o faltas de armonía en el o los sistemas jurídicos, sea para permitir la aplicación del derecho en general a los hechos o en particular a casos que no 'caben' dentro del o de los sistemas jurídicos), sobreviviría también la tópica. Por doquier, pues, persiste y reaparece la tópica, la invención, la interpretación. El sistema jurídico moderno, por lo tanto, no destruye en modo alguno a la tópica, sino que sólo la hace operar en un aparente segundo plano, ocultamente. Unos deslumbrantes axiomas jurídicos, por ejemplo, no pueden dejar de ser el producto de una elección arbitraria. La lógica, por cierto, es indispensable para la jurisprudencia, pero a la hora decisiva ha de ir detrás de la invención, puesto que la tópica precede a la lógica. Por ende: nada hace suponer que los intentos de transformar a la jurisprudencia en ciencia estricta y sistemática vayan a tener éxito. Es necesario, se ve de lo dicho, elaborar una ciencia de la jurisprudencia que no desnaturalice su estilo tópico, su constante y aproximativa búsqueda de lo justo.

Viehweg ve que la jurisprudencia siempre posee algunos tópicos relevantes y que deja de lado aquéllos que no le resultan provechosos; sin embargo, el cambio de las situaciones puede llevar a que tópicos irrelevantes pasen a ser importantes, y viceversa (sea por intermedio de la legislación, o por medio de la interpretación). El saber jurídico, sintetiza, tiende a flexibles grados de fijeza. Ya que su problema fundamental, su crucial aporía es qué sea lo justo aquí y ahora, en el campo ilimitado de las situaciones. Problema que, por lo demás, no es susceptible de sistematización, por razón de su constante e irreductible presencia y permanencia. De ahí que la total fisonomía de la jurisprudencia penda del problema y que sus conceptos y proposiciones (y su implicación) estén vinculados y hayan de ser comprendidos desde el problema, 
conclusiones éstas que pueden encontrar abundante demostración en la civilística contemporánea.

Viehweg, en suma, constata que desde los años 50 se ha verfificado un vuelco hacia la tópica, la retórica (ejemplo de lo cual, a más de su propia obra, son Perelman y Olbrechts-Tyteca), las cuales predominan in praxi y suministran frecuentemente in casu la decisión adecuada y que, para decirlo en fórmula breve, aspiran a una 'creatividad controlable', a una 'argumentación razonable'. Si bien resulta posible aplicar la lógica formal en el ámbito jurídico, la lógica del derecho supera con creces los deslindes de la lógica estricta. Aunque de la relación entre invención (o argumentación) y deducción surge el pensamiento jurídico, debe agregarse que la deducción es insuficiente para la jurisprudencia y, más aún, que la argumentación carga en ella con la mayor responsabilidad.

b) Perelman, ya mencionado por Viehweg, ha elaborado una nueva retórica cuyo objeto de estudio es la argumentación. A su modo de ver, el razonamiento jurídico es a radice argumentativo: la lógica jurídica, en especial la judicial, no es lógica formal, sino argumentación, muy ligada -por lo demás- con la idea que tienen los jueces y legisladores de su propia labor, del derecho y de su función social. Al contrario del razonamiento puramente formal, dice Perelman, el pensamiento jurídico es siempre controvertido, motivo por el cual es muy difícil considerarlo como correcto o incorrecto. La nueva retórica, en concreto, estudia los presupuestos de la argumentación (sean sus elementos -orador, discurso y auditorio-, sean sus géneros -deliberativo, judicial y epidíctico-), sus puntos de partida (que son los tópicos, además de lo cual se examinan los distintos tipos de acuerdo sobre las premisas y los modos como éstas se presentan) y las numerosas y diversas técnicas discursivas - de asociación o disociación- que tratan de provocar o acrecentar eficazmente la adhesión de un determinado auditorio a tesis que se presentan para su asentimiento. Esta adhesión que suscita la argumentación, por cierto, no depende sólo de que la tesis sea verdadera, sino también de que parezca equitativa, oportuna, actual, razonable, plausible, mejor adaptada a la situación. La nueva retórica no cree que el juez haga meras deducciones silogísticas; más bien procura que el juez consiga, en cada caso, una solución equitativa y razonable, pero sin ir más allá de lo que su sistema de derecho le autoriza a hacer. El juez ha de hacer una síntesis entre la equidad y la ley, pudiendo 'dulcificar' a esta última a través de las reglas jurídicas no escritas, es decir, mediante los principios generales del derecho y los tópicos jurídicos. La argumentación tiene que hacer aceptable la decisión judicial y, a la vez, debe poner de manifiesto la conformidad de esta decisión con el derecho vigente, mostrando que la mejor interpretación de la ley se concilia perfectamente con la mejor solución del caso concreto. La argumentación, en suma, intenta evitar los extremos de lo rígidamente necesario y de lo meramente arbitrario ${ }^{159}$.

c) Otra de las aproximaciones razonables al pensamiento jurídico es la de la hermenéutica. A partir de Schleiermacher, Dilthey, Heidegger y Gadamer, la hermenéutica jurídica no ha dejado de destacar la relevancia que la situación vital tiene para

\footnotetext{
${ }^{159}$ La de Perelman, por supuesto, no es la única teoría de la argumentación que se haya propuesto en los últimos decenios, pues ella conoce diversas versiones. Schneider y Schroth, por dar un ejemplo, distinguen tres versiones: una prescriptiva (como la de Alexy), otra comprensiva (como la de Neumann) y otra empírica (tal como la que ha dirigido, en München, Arthur Kaufmann). Estos autores reconocen otras tantas versiones de la teoría de la decisión (ya que debe tomarse en cuenta que toda argumentación conduce naturalmente a una decisión).
} 
la comprensión, el arraigo de la comprensión en la estructura existencial del Dasein y su apertura al ser, el hecho inamisible de que toda comprensión supone una precomprensión (por razón de lo cual se produce un ir y venir circular entre el comprensor y lo comprendido, de modo que uno y otro resultan transformados en la comprensión es justo el círculo hermenéutico-) y la dimensión creativa que posee en particular la interpretación. Ahora bien: según Schroth, la hermenéutica jurídica ha asumido, en el marco de la aplicación del derecho y, más en concreto, de la interpretación normativa. la tarea de salvar la distancia que hay entre la generalidad de la norma y las particularidades de los casos. $Y$ en dicha tarea, agrega Schroth, se ha topado con numerosos problemas. Uno de ellos es el del significado que tienen las normas de cara al juzgamiento de los casos concretos (dentro de lo cual este autor adopta la teoría de Wittgenstein del significado como uso, atendiendo al modo como se utilizan los signos). Otro problema es el de los criterios de decisión que cotidianamente se utilizan en la aplicación del derecho, dando especial énfasis al papel que juegan los precedentes judiciales (también llamados 'normas del caso'). Otro problema es el de la interpretación o, más precisamente, el del establecimiento y comprobación de los criterios de aplicación de las normas. Se presentan aquí varias cuestiones: ¿cuáles han sido y son hoy los elementos -o, en otras palabras, la meta y los medios- de la interpretación?. ¿qué es lo que hace necesaria la interpretación de un texto?, ¿cómo se formulan las hipótesis o criterios interpretativos?, ¿de qué manera se adopta uno de los criterios -sobretodo cuando existen hipótesis encontradas- y se decide un caso particular?, ¿cuáles son los límites que han de respetarse en la aplicación del derecho, en la concreción de las normas?, ¿cómo debe presentarse la decisión en favor de un determinado criterio interpretativo? Otro nuevo problema es el que se refiere a las consecuencias de una decisión -tanto sus consecuencias jurídicas como las consecuencias de las consecuencias jurídicas (o 'efectos adaptativos') - y a la existencia de criterios interpretativos o bien indeterminados o bien no perceptibles por la simple observación sino por el examen de ciertas disposiciones que están presentes en la conducta humana (conceptos, por lo tanto, 'dispositivos').

d) Villey, a su turno, también en pleno camino razonable, postula que la metodología jurídica es dialéctica. En su opinión -sintetizada por Rabbi-Baldi-, desde el siglo XVII hasta hoy se ha pretendido que el derecho es un sistema perfectamente racional, coherente, homogéneo y cierto, que sus conocimientos han de ser estrictamente científicos y sistemáticos y que a la solución de los casos debe preceder una deducción lógicamente impecable. Contemporáneamente, pues, derecho no es lo justo ni nada semejante, sino conjunto de reglas. Para Villey, en cambio, el derecho no es ciencia ni mera retórica, sino algo que está a medio camino entre ambas, una metodología para el discernimiento de lo que es justo: la dialéctica. ¿En qué consiste? Dialéctica proviene de dialégesthai, que significa discutir, disputar, tratar, conversar. La dialéctica -el diálogo- permite conocer los diversos puntos de vista, enfrentarlos y, así, aprehender en lo posible la verdad de las cosas. Fue aquella parte de la lógica aristotélica caracterizada tanto por la incertidumbre y el problematismo de sus premisas cuanto por la importancia que en estos razonamientos posee la interrogación y la confrontación de las opiniones. La dialéctica, dice Villey, implica un enfrentamiento de opiniones enderezado a la búsqueda de la adecuación entre el intelecto y las cosas que esto es la verdad-. Así caracterizada, la dialéctica resulta insustituible en el mundo del derecho, ya que es la única metodología adecuada a la naturaleza del derecho: la de una realidad en constante y tenso disparo hacia lo justo. Por lo mismo, la dialéctica no 
consiste en una arbitraria y antojadiza conversación, sino en una discusión perfectamente ordenada de acuerdo a determinadas reglas. Dichas reglas dicen relación con los siguientes aspectos:

- determinación del problema o de la pregunta: es la fijación, con la mayor claridad que sea posible, del caso o cuestión que se debate, caso o cuestión que han de ser reales y no meramente nominales;

- selección de los participantes: son las partes, representadas por expertos en la materia, y un tercero imparcial, que, sirviéndose de la ley, va más allá de ella y decide qué es lo justo en el caso que se le ha sometido;

- desarrollo de la argumentación y selección de las autoridades: pues cada experto defiende a su parte recurriendo al auxilio de distintas autoridades, sean los edictos, o los senado consultos, o leyes privadas, o las costumbres, o los tópicos;

- confrontación de las opiniones: ya que si cada experto defiende a su parte ocultando aquello que la desfavorece, es porque el juez, a través de los múltiples puntos de vista que van apareciendo en la argumentación, puede contemplar así la cosa, el problema desde todas las perspectivas posibles $y$, a la vez, puede permitir la determinación mutua del derecho y la norma y, de este modo, concretar pero también crear el derecho del caso; y

- conclusión: es la sentencia del juez, que si bien no es más que una opinión provista de un valor relativo, cuya aplicación a otros casos ha de realizarse con mucha prudencia y cuidado, constituye de todas maneras el resultado de un proceso vivo y constante, del que participan personas muy calificadas, que actúan en conjunto, y que permite la integración de diversos puntos de vista en una perspectiva más alta y completa del problema concreto que se ha examinado.

e) Recaséns Siches, al fin, es otro de los que bosqueja una lógica de lo razonable. Para él, el derecho es un arte práctico, una técnica de control social. Por eso, las normas de derecho no pueden ser catalogadas de verdaderas o falsas, si bien pueden y deben ser juzgadas desde el ángulo de otros valores (como la justicia, la libertad, etc.). Además, siendo un instrumento práctico, el derecho debe expulsar de sí a la lógica formal. Esta, en efecto, no agota todas las posibilidades de la inteligencia ni es un medio adecuado para tratar o resolver los asuntos prácticos, en los cuales se procura comprender significaciones como también descubrir, elegir y realizar valoraciones y finalidades. El derecho no puede ser reducido a un sistema lógico y coherente, y el juez no puede conformarse con el puro auxilio de la lógica, pues con frecuencia crea la norma pertinente para el caso, resuelve contradicciones normativas o llena alguna laguna jurídica. Se necesita, según Recaséns, un pensar que sea problemático, tópico, dialogante, prudente, deliberativo y argumentativo, una verdadera lógica de lo razonable, que considere las particularidades de la conducta humana en sociedad, algo así como la dialéctica clásica.

\section{Bibliografía}

Adomeit, Klaus, Introducción a la teoría del Derecho (trad. Enrique Bacigalupo, Civitas, Madrid 1984). 
Alchourrón, Carlos y Bulygin, Eugenio, Von Wright y la filosofía del derecho, en Análisis lógico y derecho (Centro de Estudios Constitucionales, Madrid 1991).

Atienza, Manuel, Sobre la analogía en el Derecho (Civitas, Madrid 1986).

Atienza, Manuel, Introducción al Derecho (Barcanova, Barcelona 1991).

Ballester, Manuel, La unidad del pensamiento. Estudio sobre el itinerario intelectual de G. Kalinowski (PPU, Barcelona 1992).

Bobbio, Norberto y Conte, A. G., Derecho y lógica. Bibliografía de lógica jurídica (1936-1960) (trad. Alejandro Rossi, Centro de Estudios Filosóficos-UNAM, México 1965).

Bulygin, Eugenio, Sobre la estructura lógica de las proposiciones de la ciencia del derecho, en Análisis lógico y derecho (Centro de Estudios Constitucionales, Madrid 1991).

Bulygin, Eugenio, Validez y positivismo, en Análisis lógico y derecho (Centro de Estudios Constitucionales, Madrid 1991).

Engisch, Karl, Introducción al pensamiento jurídico (trad. Ernesto Garzón Valdés, Guadarrama, Madrid 1967).

Fiedler, Herbert, Derecho, lógica, matemática (trad. Eugenio Bulygin y Ernesto Garzón Valdés, Fontamara 1991).

Haft, Fritjof, Derecho y lenguaje, en VV.AA., El pensamiento jurídico contemporáneo (trad. Juan Antonio García, Debate, Madrid 1992).

2.

Hernández Gil, Antonio, Metodología de la Ciencia del Derecho (Madrid 1971)

Hübner, Jorge Iván, Introducción a la teoría de la norma jurídica (Jurídica de Chile, Santiago de Chile 1951). Chile 1966).

Hübner, Jorge Iván, Introducción al Derecho (Jurídica de Chile, Santiago de

Husserl, Edmund, Investigaciones lógicas (trad. Manuel García Morente y José Gaos, Revista de Occidente, Madrid 1967) 1.

Kalinowski, Georges, Introducción a la lógica jurídica (trad. Juan Casaubón, EUDEBA, Buenos Aires 1973).

Kalinowski, Georges, Lógica del discurso normativo (trad. Juan Ramón Capella, Tecnos, Madrid 1975).

Kalinowski, Georges, El problema de la verdad en la moral y en el derecho (trad. Enrique Marí, EUDEBA, Buenos Aires 1979).

Kalinowski, Georges, Ley y derecho, en Concepto, fundamento y concreción del derecho (trad. Catalina Arias, Abeledo-Perrot, Buenos Aires 1982).

Kaufmann, Arthur, Panorámica histórica de los problemas de la filosofía del derecho, en VV.AA., El pensamiento jurídico contemporáneo (trad. María Virginia Martínez y Gregorio Robles, Debate, Madrid 1992). 
Kelsen, Hans, Teoría Pura del Derecho (trad. Roberto Vernengo, PorrúaUNAM, México 1991).

Klug, Ulrich, Lógica jurídica (trad. J. C. Gardella, Temis, Bogotá 1990).

Larenz, Karl, Metodología de la Ciencia del Derecho (trad. Marcelino Rodríguez, Ariel, Barcelona 1994).

Legaz y Lacambra, Luis, Filosofía del Derecho (Bosch, Barcelona 1972).

Manson, Manuel, La lógica jurídica formal en Chile, en Anuario de Filosofía Jurídica y Social 1 (1983).

Manson, Manuel, Millas, la definición del Derecho, la filosofía jurídica y la lógica formal, en Anuario de Filosofía Jurídica y Social 2 (1984).

Manson, Manuel, Kelsen y la lógica jurídica formal (Edeval, Valparaíso 1984).

Massini, Carlos, Una contribución contemporánea a la filosofía de la ley: las investigaciones de Georges Kalinowski, en Persona y Derecho 15 (1986).

Massini, Carlos, Lenguaje de las normas y Derecho natural. Consideraciones sobre Georges Kalinowski y la semántica normativa, en Anuario de Filosofía del Derecho 10 (1993).

Massini, Carlos, Filosofía del Derecho (Abeledo-Perrot, Buenos Aires 1994).

Montoro, Alberto, Aproximación al estudio de la lógica jurídica (Secretariado de Publicaciones-Universidad de Murcia, Madrid 1986).

Neumann, Ulfrid, Lógica jurídica, en VV.AA., El pensamiento jurídico contemporáneo (trad. Gregorio Robles, Debate, Madrid 1992).

Perelman, Chaïm, La lógica jurídica y la nueva retórica (trad. Luis Diez-Picazo, Civitas, Madrid 1988).

Philipps, Lothar, Teoría de las normas, en VV.AA., El pensamiento jurídico contemporáneo (trad. Renato Rabbi-Baldi, Debate, Madrid 1992).

Quintana, Fernando, La hermenéutica y el derecho, en VV.AA., Filosofía del derecho (Edeval, Valparaíso 1980). 1990).

Rabbi-Baldi, Renato, La filosofía jurídica de Michel Villey (EUNSA, Pamplona

Recaséns Siches, Luis, Nueva filosofía de la interpretación del Derecho (Porrúa, México 1980). 1985).

Recaséns Siches, Luis, Introducción al estudio del Derecho (Porrúa, México

Ross, Alf, Lógica de las normas (trad. José Hierro, Tecnos, Madrid 1971).

Schneider, Jochen y Schroth, Ulrich, Perspectivas en la aplicación de las normas jurídicas: determinación, argumentación y decisión, en VV.AA., El pensamiento jurídico contemporáneo (trad. María José Fariñas, Debate, Madrid 1992). 
Schroth, Ulrich, Hermenéutica filosófica y jurídica, en VV.AA., El pensamiento jurídico contemporáneo (trad. Juan Antonio García, Debate, Madrid 1992).

Skariça, Mirko, Elementos lógicos para la elaboración de una norma jurídica (inédito).

Viehweg, Theodor, Tópica y jurisprudencia (trad. Luis Díez-Picazo, Taurus, Madrid 1986).

Viehweg, Theodor, Tópica y Filosofía del Derecho (trad. Jorge Seña, Gedisa, Barcelona 1991). 1979).

Wright, Georg Henrik von, Norma y acción (trad. Pedro García, Tecnos, Madrid 